\title{
A RESPONSABILIDADE CIVIL DO ESTADO POR OMISSÃO NO CONTEXTO DA PANDEMIA DE COVID-19 NO BRASIL
}

\author{
Julia Soares Mafra ${ }^{1}$ \\ Maria Eduarda Vieira Schug da Silva ${ }^{2}$ \\ Rafaela Borgo Koch Schlickmann ${ }^{3}$ \\ Recebido em 21/06/2021 \\ Aceito em 18/08/2021
}

\section{RESUMO}

A temática do presente artigo está inserida no estudo da responsabilização civil da Administração Pública por omissões durante a crise pandêmica de Covid-19. O objetivo geral é identificar se há a possibilidade de o Estado ser responsabilizado pelos danos sociais causados por eventuais omissões de seus agentes no contexto de enfrentamento à pandemia de Covid-19, no Brasil. Os objetivos específicos são: a) analisar o conceito jurídico da Responsabilidade Civil do Estado; b) identificar quais são os pressupostos e excludentes da Responsabilidade Civil do Estado; c) pesquisar sobre a Responsabilidade Civil do Estado por omissão e possíveis precedentes; d) analisar as contribuições da Comissão de Inquérito Parlamentar da Covid-19 para identificação das omissões. Como hipótese se tem que, considerando o dano social gerado em virtude das omissões na aquisição de vacinas e no incentivo a políticas públicas de prevenção e combate à Covid-19, há a possibilidade de responsabilização civil do Estado, contudo, desde que constatados os pressupostos de responsabilização nesse contexto. Nos resultados concluiu-se que, ao final das investigações realizadas pela Comissão Parlamentar de Inquérito da Covid-19, que atualmente tramita no Senado Federal, caso evidenciadas omissões estatais ensejadoras de danos à sociedade brasileira, haverá a possibilidade de responsabilização do Estado por omissões no enfrentamento da pandemia de Covid-19.

PALAVRAS CHAVE: Responsabilidade Civil do Estado. Omissão. Covid-19.

\section{THE CIVIL LIABILITY OF THE STATE FOR OMISSION IN THE CONTEXT OF THE COVID-19 PANDEMIC IN BRAZIL}

\begin{abstract}
The theme of this article is inserted in the study of civil liability of the Public Administration for omissions during the Covid-19 pandemic crisis. The general objective is to identify whether the State is likely to be held responsible for social damage caused by any omissions by its agents in the context of fighting the Covid-19 pandemic in Brazil. The specific objectives are: a) to analyze the legal concept of civil liability of the State;
\end{abstract}

\footnotetext{
${ }^{1}$ Graduanda do sétimo período do Curso de Direito da Universidade do Vale do Itajaí - Campus de Balneário Camboriú. E-mail: mfrajulia@gmail.com.

${ }^{2}$ Graduanda do sétimo período do Curso de Direito da Universidade do Vale do Itajaí - Campus de Balneário Camboriú. E-mail: mariaeduardaschug@gmail.com.

${ }^{3}$ Doutora e Mestre em Ciência Jurídica pela Universidade do Vale do Itajaí - UNIVALI. Bacharel em Direito pela Universidade do Vale do Itajaí - UNIVALI e Especialista em Direito Processual Civil pela mesma instituição. Professora da Graduação nos cursos de Direito e Gastronomia na Universidade do Vale do Itajaí - UNIVALI. Advogada. E-mail: rafaelabkoch@univali.br.
} 
b) identify the assumptions and exclusions of State civil liability; c) researching the State's civil liability for omission and possible precedents; d) analyze the contributions of the Covid-19 Parliamentary Inquiry Committee to identify omissions. As a hypothesis, considering the social damage generated due to omissions in the acquisition of vaccines and in the encouragement of public policies to prevent and combat Covid-19, there is the possibility of civil liability of the State, however, the assumptions must be present accountability in this context. As a result, at the end of the investigations carried out by the Covid-19 Parliamentary Inquiry Commission, which is currently in the Federal Senate, if state omissions causing damage to Brazilian society are evidenced, there will be the possibility of holding the State responsible for omissions in the confrontation of the Covid-19 pandemic.

Keywords: Civil Liability of the State. Omission. Covid-19.

\section{INTRODUÇÃO}

A presente pesquisa possui como objetivo analisar se há Responsabilidade Civil estatal pelos danos causados por omissões no que concerne ao combate da pandemia da Covid-19 no Brasil. A fim de atingir o objetivo geral, são delimitados os seguintes objetivos específicos: a) analisar o conceito jurídico da Responsabilidade Civil do Estado; b) identificar quais são os pressupostos e excludentes da Responsabilidade Civil do Estado; c) pesquisar sobre a Responsabilidade Civil do Estado por omissão e possíveis precedentes; d) analisar as contribuições da Comissão de Inquérito Parlamentar da Covid-19 para identificação das omissões.

Preliminarmente, o estudo visa conceituar a Responsabilidade Civil estatal e seus pressupostos. Discorre-se sobre as excludentes da responsabilização civil do Estado. Estuda-se a Responsabilidade Civil estatal por omissão, e, por fim, a Comissão Parlamentar de Inquérito da Covid-19 e suas contribuições para a identificação de omissões.

Como hipótese se tem que, considerando o dano social gerado em virtude das omissões na aquisição de vacinas e no incentivo a políticas públicas de prevenção e combate à Covid-19, há a possibilidade de responsabilização civil do Estado, contudo, desde que constatados os pressupostos de responsabilização nesse contexto.

A problematização da pesquisa norteia-se em evidenciar como a responsabilização civil da Administração Pública por omissão de seus agentes depende da identificação clara dos pressupostos da responsabilidade, além de necessitar demonstrar a não ocorrência de alguma excludente de responsabilidade civil do Estado. Em todas as fases desta pesquisa empregou-se o método indutivo, sendo o mesmo operacionalizado através das técnicas do referente e da pesquisa bibliográfica. 


\title{
2 RESPONSABILIDADE CIVIL DO ESTADO: CONCEITUAÇÃO E PRESSUPOSTOS
}

Em um primeiro momento, a fim de entender de modo mais aprofundado como se daria a responsabilização civil estatal por atos omissivos de seus agentes no contexto pandêmico da Covid-19, deve-se contextualizar e conceituar o instituto jurídico da Responsabilidade Civil do Estado, identificando os seus pressupostos. Atualmente, a responsabilidade civil da Administração Pública alcançou o patamar de responsabilidade objetiva, independendo da culpabilidade. Contudo, no decorrer da evolução do Direito, pode ser observado que, nos primórdios, havia o princípio da irresponsabilidade absoluta do Estado (The King can do no wrong $)^{4}$. Ainda, para Rosa ${ }^{5}$ :

\begin{abstract}
A responsabilidade é um fato social porque está inserida na vida em sociedade. Independente do tipo da norma descumprida, importando a transgressão em alguma lesão, rompe-se a ordem e a harmonia social, dando margem à responsabilidade que surge como instrumento único, hábil e capaz de se retomar ao status quo ante.
\end{abstract}

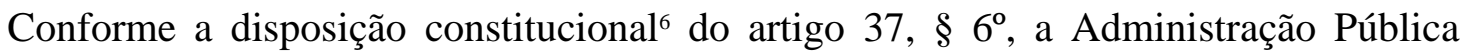
responde por danos que seus agentes, no exercício de suas atribuições, ocasionem a terceiros. Nesse sentido, conceitua Di Pietro7, a responsabilidade do "[...] Estado corresponde à obrigação de reparar danos causados a terceiros em decorrência de comportamentos comissivos ou omissivos, materiais ou jurídicos, lícitos ou ilícitos, imputáveis aos agentes públicos.”

Assim sendo, deve-se analisar os pressupostos da responsabilização civil do Estado. No âmbito da Responsabilidade Civil, existem três pressupostos básicos e fundamentais: o dano gerado a terceiro, o ato ilícito causador do dano e o nexo causal entre o dano ocasionado e o referido ato. Para a responsabilização da Administração, aplicam-se justamente os pressupostos clássicos, contudo, ressalta-se que a ilicitude do ato estatal é elemento desnecessário para a

\footnotetext{
${ }^{4}$ GONÇALVES, Carlos Roberto. Responsabilidade civil. 20. ed. São Paulo: Saraiva, 2021. n. p. Disponível em: https://app.saraivadigital.com.br/leitor/ebook:752860. Acesso em: 03 Jun. 2021.

${ }^{5}$ ROSA, Leilane Mendonça Zavarizi da. Reflexões acerca da responsabilidade civil extracontratual do Estado. p. $14 . \quad$ Disponível em: https://repositorio.ufsc.br/xmlui/bitstream/handle/123456789/76502/104834.pdf?sequence=1\&isAllowed=y. Acesso em: 03 Jun. 2021.
}

${ }^{6}$ BRASIL. Constituição da República Federativa do Brasil de 1988 . Disponível em: http://www.planalto.gov.br/ccivil_03/constituicao/constituicao.htm. Acesso em: 03 Jun. 2021.

${ }^{7}$ DI PIETRO. Maria Sylvia Zanella. Direito administrativo. 33. ed. Rio de Janeiro: Forense, 2020, p. 1488. 
configuração do dever de indenizar ${ }^{8}$; basta apenas que o ato seja praticado por agente estatal para a ocorrência da possibilidade de responsabilidade civil.

No mais, aplica-se a teoria do risco administrativo ${ }^{9}$ para a ocorrência de responsabilização por parte da Administração, que significa que - apesar de poder haver Responsabilidade Civil do Estado sem existência de culpa - é elementar a aparição do nexo de causalidade entre o dano gerado a terceiro e a atitude danosa do agente público.

Assim sendo, pode-se observar que a Responsabilidade Civil do Estado não tem ocorrência universal, isto é, necessita da configuração clara de seus pressupostos, principalmente em relação ao nexo de causalidade.

No mais, sobre o dever de indenizar decorrente de omissões por parte da Administração, deve sempre ser observada a ocorrência específica de uma inação geradora de dano, não sendo admitida a configuração de Responsabilidade Civil do Estado por uma omissão abstrata ou genérica.

Contudo, mesmo sendo observados todos os requisitos de configuração da responsabilidade, existem certas circunstâncias que são capazes de atenuar ou, até mesmo excluir, o dever de indenizar do Estado, circunstâncias essas que merecem destaque e necessitam ser analisadas.

\subsection{EXCLUDENTES DA RESPONSABILIDAÇÃO CIVIL DO ESTADO}

A ocorrência de nexo causal é pressuposto elementar para a responsabilização civil do Estado, como visto. Nesse contexto, o nexo deixa de existir - ou passa a gerar reflexos reduzidos - quando a Administração Pública não for a causadora do dano ou quando, junto com o poder público, existirem outras ensejadoras do dano, sendo apontadas como causas que excluem a responsabilidade a força maior, a culpa exclusiva da vítima e a culpa de terceiro. ${ }^{10}$

A primeira excludente, a força maior, se trata de fato que "[...] se prevê ou é previsível, mas não se pode, igualmente, evitar, haja vista ser mais forte do que a vontade ou ação do homem." ${ }^{11}$ Assim sendo, ao se falar de ocorrência de força maior, há a referência a evento

${ }^{8}$ SUPREMO TRIBUNAL FEDERAL. Recurso extraordinário n. 113587. Disponível em: https://jurisprudencia.stf.jus.br/pages/search/sjur67244/false. Acesso em : 03 Jun. 2021.

${ }^{9}$ FARIAS, Cristiano Chaves de; ROSENVALD, Nelson. Novo tratado de responsabilidade civil. 4. ed. São Paulo: Saraiva, 2019.

${ }^{10}$ DI PIETRO. Maria Sylvia Zanella. Direito administrativo. 33. ed. Rio de Janeiro: Forense, 2020, p. 1503.

${ }^{11}$ ARAÚJO, Eugênio Rosa. A responsabilidade civil do Estado por omissão e suas excludentes. Disponível em: http://www.mprj.mp.br/documents/20184/1240456/Eugenio_Rosa_de_Araujo.pdf. Acesso em: 03 Jun. 2021. 
danoso que pode ou não ser previsto de antemão; contudo, em qualquer um dos casos, não haverá a possibilidade evitar o prejuízo.

Em relação à culpa exclusiva da vítima, não seria razoável que o Estado fosse responsável por reparar danos gerados pela própria vítima, sem qualquer influência de atos omissivos ou comissivos por parte da Administração, pois há o rompimento do nexo de causalidade. Não obstante a possibilidade de o fato danoso decorrer apenas de atitude culpável da própria vítima, há ainda a alternativa de o dano ocorrer por influência concorrente entre vítima e Estado. Nessa última possibilidade, não há de se falar em excludente de responsabilidade civil, mas de uma atenuante. Assim, o ente estatal “[...] responde proporcionalmente ao grau de culpa do seu agente. Há a repartição de responsabilidades e o juiz fixa a indenização de forma proporcional, respondendo o Estado apenas pelos danos a que deu causa." 12

Ainda, há a excludente do ato (ou culpa) de terceiro ${ }^{13}$, ou seja, da ocasião em que o dano não é gerado por agente do Estado, desaparecendo o nexo causal, haja vista que, novamente, não seria a Administração a ensejadora do prejuízo.

Para Araújo $^{14}$, há ainda mais uma espécie de excludente de responsabilidade civil do ente estatal, que seria o caso fortuito, sendo conceituado como:

\begin{abstract}
Fortuito, do latim fortuitus, de fors, quer dizer casual, acidental, ao azar. É, no sentido exato de sua derivação, o caso que não se poderia prever e se mostra superior às forças ou vontade do homem para que pudesse evitá-lo. [...] No entanto, modernamente, entende-se que somente o caso fortuito externo, ligado à força maior, o Act of God dos ingleses, estranho à pessoa do agente e da máquina administrativa, é capaz de excluir a responsabilidade do agente. [...] $\mathrm{O}$ caso fortuito interno, ligado à pessoa, à coisa ou à empresa do agente, não constitui excludente de responsabilidade, porque este seria previsível e ligado à pessoa (quando ocorre um mal súbito, por exemplo) ou à máquina (defeitos mecânicos, por exemplo).
\end{abstract}

Por conseguinte, após aclaradas as incorrências de excludente de responsabilidade, deve-se conceituar de maneira mais minuciosa a responsabilização civil do Estado por omissão, bem como identificar a aplicação prática desse instituto em inações estatais.

\footnotetext{
${ }^{12}$ ARAÚJO, Eugênio Rosa. A responsabilidade civil do Estado por omissão e suas excludentes. Disponível em: http://www.mprj.mp.br/documents/20184/1240456/Eugenio_Rosa_de_Araujo.pdf. Acesso em: 03 Jun. 2021.

${ }^{13}$ DI PIETRO. Maria Sylvia Zanella. Direito administrativo. 33. ed. Rio de Janeiro: Forense, 2020.

${ }^{14}$ ARAÚJO, Eugênio Rosa. A responsabilidade civil do Estado por omissão e suas excludentes. Disponível em: http://www.mprj.mp.br/documents/20184/1240456/Eugenio_Rosa_de_Araujo.pdf. Acesso em: 03 Jun. 2021.
} 


\title{
3 RESPONSABILIDADE CIVIL DO ESTADO POR OMISSÃO
}

No tocante à omissão, entende-se que somente haverá caracterizada esta modalidade quando restarem comprovados os elementos da culpa, e para isso, Carvalho Filho ${ }^{15}$ ensina que

[...]quando a conduta estatal for omissiva, será preciso distinguir se a omissão constitui, ou não, fato gerador da responsabilidade civil do Estado. Nem toda conduta omissiva retrata um desleixo do Estado em cumprir um dever legal; se assim for, não se configurará a responsabilidade estatal. Somente quando o Estado se omitir diante do dever legal de impedir a ocorrência do dano é que será responsável civilmente e obrigado a reparar os prejuízos.

Ainda, clarifica-se o ato omissivo como sendo, segundo Marinela ${ }^{16}$

\begin{abstract}
Nas condutas omissivas, no não fazer do Estado, hoje a doutrina e a jurisprudência dominantes reconhecem a aplicação da teoria da responsabilidade subjetiva, estando assim o dever de indenizar condicionado à comprovação do elemento subjetivo, a culpa e o dolo, admitindo a aplicação da culpa anônima ou culpa do serviço, que se contenta com a comprovação de que o serviço não foi prestado ou foi prestado de forma ineficiente ou atrasada.
\end{abstract}

Como já visto anteriormente, a omissão estatal configura-se em Responsabilidade Civil subjetiva, uma vez que para comprová-la, necessita dos três elementos comprovados: negligência, dano e nexo causal, e nesse sentido, Mazza $^{17}$ discorre que, nos casos de dano por omissão, é devida a indenização quando a vítima deixar comprovado que o prejuízo foi gerado pela omissão, nos termos da teoria objetiva.

Ainda, no que tange ao dever de indenizar por omissões estatais, a Administração Pública apenas responde por alguns tipos de omissões, sendo, nesse caso, as específicas, diretas e concretas, sendo impossível a Responsabilização Civil do Estado por uma omissão genérica. ${ }^{18}$ A necessidade de ser evidenciada omissão específica para a configuração de Responsabilidade Civil do Estado por omissão torna ainda mais nítida a primordialidade de existência de um nexo de causalidade de maneira cristalina entre o dano e a inação estatal. Sobre o tema da omissão estatal, lecionam Netto, Farias e Rosenvald ${ }^{19}$ :

\footnotetext{
${ }^{15}$ FILHO, José dos Santos Carvalho. Manual de Direito Administrativo. 33. ed. São Paulo: Atlas, 2019. p. 832. ${ }^{16}$ MARINELA, Fernanda. Direito administrativo. 12. ed. São Paulo: Sarava Educação, 2018. p. 1.060.

${ }^{17}$ MAZZA, A. Manual de direito administrativo. 10. ed. São Paulo: Saraiva, 2020.

${ }^{18}$ FARIAS, Cristiano Chaves de. NETTO, Felipe Braga. ROSENVALD, Nelson. Manual de direito civil: Volume Único. 5. ed. Salvador: Editora Juspodivm. 2020. p. 308.

${ }^{19}$ FARIAS, Cristiano Chaves de. NETTO, Felipe Braga. ROSENVALD, Nelson. Manual de direito civil: Volume Único. p. 308.
} 
São muitas e complexas as questões envolvem a responsabilidade civil do Estado por omissão. Entre outros fatores que podem ajudar a solucionar a controvérsia está a seguinte questão: o Estado tinha o dever de evitar o dano? A jurisprudência constata, em muitos casos, que o Estado deve responder civilmente pelos danos decorrentes de sua omissão, pois deveria evitar o fato lesivo e não evitou.

No que diz respeito à necessidade de haver omissão específica para configurar a Responsabilidade Civil do estado, colaciona-se o julgado do STF acerca do tema:

\begin{abstract}
Agravo regimental nos embargos de divergência do agravo regimental no recurso extraordinário. 2. Direito Administrativo. 3. Responsabilidade civil do Estado por omissão. Teoria do Risco Administrativo. Art. 37, § $6^{\circ}$, da Constituição. Pressupostos necessários à sua configuração. Demonstração da conduta, do dano e do nexo causal entre eles. 4. Omissão específica não demonstrada. Ausência de nexo de causalidade entre a suposta falta do serviço e o dano sofrido. Necessidade do revolvimento do conjunto fático probatório dos autos. Incidência da Súmula 279/STF. 5. Agravo regimental a que se nega provimento. ${ }^{20}$
\end{abstract}

Com isso, subentende-se que a Responsabilidade Civil do Estado por omissão, conforme Rossi $^{21}$, refere-se à atitude ilícita por parte da Administração, fora dos padrões esperados, materializada pela omissão, sendo enquadrado como um poder de agir não efetivado.

Esse poder de agir a fim de evitar o dano se amolda à proposta inicial da presente pesquisa, uma vez que, diante de um cenário pandêmico totalmente novo e inesperado, esperase a ação do Estado para combater a situação, garantindo à população os métodos farmacológicos e não farmacológicos eficazes por comprovação científica a fim de evitar - ou pelo menos atenuar - os possíveis danos sociais decorrentes da proliferação do vírus da Covid19, o que está sendo investigado pela Comissão Parlamentar de Inquérito da Pandemia, haja vista a ocorrência de suposta omissão estatal no que tange à aplicação de políticas públicas efetivas para o enfrentamento da problemática.

\title{
4 A COMISSÃo PARLAMENTAR DE INQUÉRITO DA COVID-19 E SUAS CONTRIBUIÇÕES PARA IDENTIFICAÇÃO DE OMISSÕES
}

Em um primeiro momento, é oportuno trazer a conceituação jurídica do que vem a ser uma Comissão Parlamentar de Inquérito (CPI).

\footnotetext{
${ }^{20}$ SUPREMO TRIBUNAL FEDERAL. Recurso Extraordinário n. 677139. Disponível em: https://jurisprudencia.stf.jus.br/pages/search/sjur332411/false. Acesso em: 17 jun. 2021.
}

${ }^{21}$ ROSSI, Licínia. Manual de direito administrativo. 6. ed. São Paulo: Saraiva, 2020.

Ponto de Vista Jurídico | Caçador | v.10 | nº 1 | p. 110 - 120 | jan./jun. 2021 
Conforme o artigo $58, \S 3^{\circ}$, da CRFB $/ 1988^{22}$, uma CPI detém poderes de investigação inerentes a autoridades judiciais, além de outros poderes previstos no regimento interno da referida Casa Legislativa, sendo criada pela Câmara dos Deputados e pelo Senado Federal, em conjunto ou não, por requerimento de um terço dos membros a fim de apurar determinado fato por prazo certo, sendo que o relator deverá elaborar as conclusões e fazer a remessa ao Ministério Público, objetivando a responsabilização civil ou criminal dos infratores. Sobre o tema das Comissões Parlamentares de Inquérito, ressalta-se a lição de Gomes ${ }^{23}$ :

\begin{abstract}
As CPI's podem ser compreendidas como órgãos colegiados, temporários e auxiliares das Casas Legislativas que têm por objetivo investigar fato certo em tempo determinado. As motivações que justificam a instauração das CPI's são temáticas e de interesse público que podem ser dotadas de natureza política, jurídica ou administrativa. [...] As CPI's são dotadas de poder instrutório, ou seja, podem determinar diligências para promover a constituição do contexto probatório sobre o fato determinado investigado com algumas restrições como é o caso da escuta telefônica, que somente é possível por ordem judicial.
\end{abstract}

Assim sendo, após se ter clara a conceituação do instituto jurídico da CPI, deve-se adentrar ao contexto da Comissão Parlamentar de Inquérito da Covid-19. A referida comissão foi instaurada em 27 de abril de 2021, haja vista os Requerimentos n. 1371/202124 e n. $1372 / 2021^{25}$, que pugnaram pelo início das investigações parlamentares a fim de apurar as atitudes comissivas ou omissivas que ensejaram danos sociais no âmbito de enfrentamento da pandemia de Covid-19. É o objetivo principal da CPI da Covid-19, conforme as informações do Senado Federal ${ }^{26}$ :

Apurar, no prazo de 90 dias, as ações e omissões do Governo Federal no enfrentamento da Pandemia da Covid-19 no Brasil e, em especial, no agravamento da crise sanitária no Amazonas com a ausência de oxigênio para os pacientes internados; e as possíveis irregularidades em contratos, fraudes em licitações, superfaturamentos, desvio de recursos públicos, assinatura de contratos com empresas de fachada para prestação de serviços genéricos ou fictícios, entre outros ilícitos, se valendo para isso de recursos originados da União Federal, bem como outras ações ou omissões

\footnotetext{
${ }^{22}$ BRASIL. Constituição da República Federativa do Brasil. Disponível em: http://www.planalto.gov.br/ccivil_03/constituicao/constituicao.htm. Acesso em: 17 jun. 2021

${ }^{23}$ GOMES, Fabrício Ponte. Aspectos pontuais sobre o poder de investigação das Comissões Parlamentares de Inquéritos - CPI's e o papel do Ministério Público. Disponível em: http://www.mpce.mp.br/wpcontent/uploads/2018/07/ASPECTOS-PONTUAIS-SOBRE-O-PODER-DE-INVESTIGA\%C3\%87\%C3\%83ODAS-OMISS\%C3\%95ES-PARLAM.pdf. Acesso em: 17 jun. 2021.
}

${ }^{24}$ SENADO FEDERAL. Requerimento n. 1371, de 2021. Disponível em: https://www25.senado.leg.br/web/atividade/materias/-/materia/148070. Acesso em: 17 jun. 2021.

${ }^{25}$ SENADO FEDERAL. Requerimento n. 1372, de 2021. Disponível em: https://www25.senado.leg.br/web/atividade/materias/-/materia/148071. Acesso em: 17 jun. 2021.

${ }^{26}$ SENADO FEDERAL. CPI da Pandemia. Disponível em: https://legis.senado.leg.br/comissoes/comissao?codcol=2441. Acesso em: 17 jun. 2021. 
cometidas por administradores públicos federais, estaduais e municipais, no trato com a coisa pública, durante a vigência da calamidade originada pela Pandemia do Coronavírus "SARS-CoV-2", limitado apenas quanto à fiscalização dos recursos da União repassados aos demais entes federados para as ações de prevenção e combate à Pandemia da Covid-19, e excluindo as matérias de competência constitucional atribuídas aos Estados, Distrito Federal e Municípios.

Nos termos do plano de trabalho ${ }^{27}$, elaborado pelo Relator Senador Renan Calheiros, a CPI visa apurar as medidas da Administração Pública durante a Pandemia de Covid-19, tendo como linhas gerais de investigação, sem prejuízo de novos fatos conexos que possam surgir no decorrer dos trabalhos: a) ações de enfrentamento à pandemia (vacinas e outras medidas para contenção do vírus); b) Estruturas de Combate à Crise (Atribuição de responsabilidades e competências); c) Colapso da saúde no Estado do Amazonas; d) Ações de prevenção e atenção à saúde indígena; e, e) Emprego de recursos federais.

Atualmente a CPI está em curso, através da oitiva das testemunhas, bem como a solicitação de documentos aos órgãos estatais a fim de apurar a ocorrência de atitudes comissivas ou omissivas do Estado que geraram dano à sociedade brasileira durante a pandemia.

Assim sendo, ao final dos trabalhos, caso constatadas omissões por parte da Administração nesse ínterim, constará no relatório final a elucidação dos fatos, encaminhandose as conclusões ao órgão ministerial, ensejando, portanto, nas medidas cabíveis no que tange à Responsabilidade Civil do Estado, tendo em vista que é totalmente cabível a responsabilização civil da Administração por danos gerados a terceiros por omissões de seus agentes.

\section{CONSIDERAÇÕES FINAIS}

A presente pesquisa teve como finalidade discorrer sobre a Responsabilidade Civil do Estado em decorrência da omissão ao enfrentamento do cenário pandêmico causado pela COVID-19. O que ensejou a pesquisa foi a crescente discussão acerca da possibilidade de responsabilização do Estado por omissões no contexto de enfrentamento da referida pandemia.

No decorrer do artigo, foi constatado que a responsabilização civil da Administração Pública se conceitua como o dever que o Estado tem em assumir os efeitos acerca dos danos gerados a terceiros, de maneira injusta, por seus agentes no exercício de suas funções. A base

\footnotetext{
${ }^{27}$ SENADO FEDERAL. Plano de trabalho. Disponível em: https://legis.senado.leg.br/sdleggetter/documento/download/636ad15c-dba0-4bcd-bca5-65af0f0ce25d. Acesso em: 17 jun. 2021.
} 
jurídica da possibilidade de responsabilizar o Estado por eventuais danos ocasionados é constitucional, conforme foi visto.

A Responsabilidade Civil da Administração passou por inúmeras modificações ao longo do tempo, saindo de um contexto em que, inicialmente, sequer era possível responsabilizar o Estado para o atual entendimento de que é cabível a responsabilização estatal independentemente de culpa, inclusive nos atos omissivos ensejadores de danos a terceiros.

Contudo, conforme foi analisado, a Responsabilidade Civil do Estado por omissões não ocorre em qualquer situação e de modo amplo, sendo apenas cabível diante de omissões diretas, específicas e concretas, haja vista que não cabe ao ente estatal assumir o papel de segurador universal.

Assim sendo, no âmbito da Covid-19 no Brasil, atualmente são apuradas as omissões estatais no enfrentamento pandêmico, tendo em vista a instalação da Comissão Parlamentar de Inquérito sobre o tema, que tramita no Senado Federal.

Ao final dos trabalhos da Comissão, será encaminhado o relatório à autoridade competente, nesse caso, ao Ministério Público, que deverá adotar as medidas cabíveis a fim de responsabilizar o Estado pelos danos gerados não só por suas atitudes durante a pandemia, mas, inclusive, em razão dos eventuais prejuízos à sociedade brasileira em virtude das omissões do Estado.

Portanto, o objetivo da pesquisa foi cumprido, restando a hipótese confirmada, ou seja, é possível a responsabilização do Estado por omissões no contexto da pandemia de Covid-19.

\section{REFERÊNCIAS}

ARAÚJO, Eugênio Rosa. A responsabilidade civil do Estado por omissão e suas excludentes. Disponível em: http://www.mprj.mp.br/documents/20184/1240456/Eugenio_Rosa_de_Araujo.pdf. Acesso em: 03 jun. 2021.

BRASIL. Constituição da República Federativa do Brasil de 1988. Disponível em: http://www.planalto.gov.br/ccivil_03/constituicao/constituicao.htm. Acesso em: 03 jun. 2021.

DI PIETRO, Maria Sylvia Zanella. Direito administrativo. 33. ed. Rio de Janeiro: Forense, 2020

FARIAS, Cristiano Chaves de. NETTO, Felipe Braga. ROSENVALD, Nelson. Manual de direito civil: Volume Único. 5. ed. Salvador: Editora Juspodivm. 2020. p. 308.

FARIAS, Cristiano Chaves de. ROSENVALD, Nelson. Novo tratado de responsabilidade civil. 4. ed. São Paulo: Saraiva, 2019. 
FILHO, José dos Santos Carvalho. Manual de Direito Administrativo. 33. ed. São Paulo: Atlas, 2019.

GOMES, Fabrício Ponte. Aspectos pontuais sobre o poder de investigação das Comissões Parlamentares de Inquéritos - CPI's e o papel do Ministério Público. Disponível em: http://www.mpce.mp.br/wp-content/uploads/2018/07/ASPECTOS-PONTUAIS-SOBRE-OPODER-DE-INVESTIGA\%C3\%87\%C3\%83O-DAS-OMISS\%C3\%95ES-PARLAM.pdf. Acesso em: 17 jun. 2021.

GONÇALVES, Carlos Roberto. Responsabilidade civil. 20. ed. São Paulo: Saraiva, 2021.

MARINELA, Fernanda. Direito administrativo. 12. ed. São Paulo: Sarava Educação, 2018.

MAZZA, A. Manual de direito administrativo. 10. ed. São Paulo: Saraiva, 2020.

ROSA, Leilane Mendonça Zavarizi da. Reflexões acerca da responsabilidade civil extracontratual do Estado. p. 14. Disponível em: https://repositorio.ufsc.br/xmlui/bitstream/handle/123456789/76502/104834.pdf?sequence=1 \&isAllowed=y. Acesso em: 03 jun. 2021.

ROSSI, Licínia. Manual de direito administrativo. 6. ed. São Paulo: Saraiva, 2020.

SENADO FEDERAL. CPI da Pandemia. Disponível em: https://legis.senado.leg.br/comissoes/comissao?codcol=2441. Acesso em: 17 jun. 2021.

SENADO FEDERAL. Plano de trabalho. Disponível em: https://legis.senado.leg.br/sdleggetter/documento/download/636ad15c-dba0-4bcd-bca5-65af0f0ce25d. Acesso em: 17 jun. 2021.

SENADO FEDERAL. Requerimento n. 1371, de 2021. Disponível em: https://www25.senado.leg.br/web/atividade/materias/-/materia/148070. Acesso em: 17 jun. 2021.

SENADO FEDERAL. Requerimento n. 1372, de 2021. Disponível em: https://www25.senado.leg.br/web/atividade/materias/-/materia/148071. Acesso em: 17 jun. 2021.

SUPREMO TRIBUNAL FEDERAL. Recurso extraordinário n. 113587. Disponível em: https://jurisprudencia.stf.jus.br/pages/search/sjur67244/false. Acesso em: 03 jun. 2021.

SUPREMO TRIBUNAL FEDERAL. Recurso extraordinário n. 677139. Disponível em: https://jurisprudencia.stf.jus.br/pages/search/sjur332411/false. Acesso em: 17 jun. 2021. 